\title{
NILAI EKONOMI PEMANFAATAN AIR RUMAHTANGGA DI KECAMATAN KRADENAN, KABUPATEN GROBOGAN
}

\author{
(Value of Economic Utilization of Household Water in Kradenan Sub District, \\ Grobogan Districs)
}

\author{
Nur Ainun Jariyah' \& Purwanto²
}

\begin{abstract}
Grobogan Regency is one of the regencies in Central Java that experiences water problems during the dry season due to hydrometeorological drought. The purpose of this study was to determine the economic value of household water use in Kradenan District, Grobogan Regency. The research was conducted in 2018, in Springshed Mindik, Kradenan District, Grobogan Regency. Respondents in this study amounted to 42 people taken randomly with the criteria of the population in the district of Kradenan, taking water in the spring either by using a water pump or by drawing directly into the spring. Retrieval of secondary data to related agencies. Data analysis was performed by calculating the public perception on the use of water is done by assessing the willingness to pay for use of water for household needs in the form of qualitative and quantitative descriptive in springshed Mindik. The results of this study are the economic value of household water use in Kradenan sub-district as seen from the number of households that use water, the average consumption of water, the average number of family members, obtained at $R p$ 166,7 I 7,923,801.00/year.
\end{abstract}

Keywords : Drought, hydrometeorological, economic value of water, water consumption

\begin{abstract}
ABSTRAK
Kabupaten Grobogan merupakan salah satu kabupaten di Jawa Tengah yang mengalami permasalahan air ketika musim kemarau yang disebabkan karena kekeringan hidrometeorologis. Tujuan penelitian ini adalah untuk mengetahui nilai ekonomi pemanfaatan air rumah tangga di Kecamatan Kradenan, Kabupaten Grobogan. Penelitian dilaksanakan pada tahun 2018, di Springshed Mindik, Kecamatan Kradenan, Kabupaten Grobogan. Responden pada penelitian ini berjumlah 42 orang yang diambil secara acak dengan kriteria penduduk yang mengambil air di sendang baik dengan menggunakan pompa air maupun dengan menimba langsung ke sendang. Data sekunder diambil dari dinas terkait. Analisis data dilakukan dengan menghitung persepsi masyarakat pada penggunaan air yang dilakukan dengan menilai kesediaan membayar (Willingnes To Pay) atas pemanfaatan air untuk kebutuhan rumah tangga dalam bentuk deskriptif kualitatif dan kuantitatif di springshed Mindik. Hasil penelitian ini diperoleh nilai ekonomi pemanfaatan air rumah tangga sekecamatan Kradenan yang dilihat dari jumlah rumah tangga pemanfaat air, konsumsi rata-rata air, rata-rata jumlah anggota keluarga adalah sebesar Rp 166.717.923.801,00/ tahun.
\end{abstract}

Kata Kunci : Kekeringan, hidrometeorologis, nilai ekonomi air, konsumsi air

\author{
Author Institution $\quad$ : $\quad$ I\&2Peneliti Balai Penelitian dan Pengembangan Teknologi Pengelolaan Daerah Aliran Sungai Solo - \\ Jalan Ahmad Yani Pabelan, Kartasura, PO BOX 295 Surakarta, 57102, Indonesia Telp. (0370) \\ 6175552. \\ Koresponding Author : Tel.628I2298I3334; Email: Inurainun_25/3@yahoo.co.id; 2purwanto-fris@yahoo.com \\ Articel History $\quad$ : Received 10 March 2020; received in revised from 08 April 2020; accepted I3 April 2020;Available \\ online since 30 April 2020
}

http://doi.org// 0.20886/jpkf.2020.4.I.I-I0 


\section{PENDAHULUAN}

Air merupakan kebutuhan pokok setiap manusia. Air menjadi permasalahan ketika tidak dapat memenuhi kebutuhan masyarakat untuk minum, mandi, mencuci dan kebutuhan pokok lainnya (Najib, 2018; Herlambang, 2009; Susilastuti, Karno, \& Diana, 2014; Saraswaty, 20I3). Permasalahan tersebut biasanya terjadi pada musim kemarau. Kabupaten Grobogan merupakan salah satu kabupaten di Jawa Tengah yang mengalami permasalahan air ketika musim kemarau (Purwanto \& Supangat, 2017; Sriutomo \& Christanto, 20I5).

Kekeringan di Kabupaten Grobogan termasuk dalam kekeringan hidrometeorologis yaitu kekeringan yang berkaitan dengan tingkat curah hujan di bawah normal dalam satu musim di suatu kawasan dan berkaitan dengan kekurangan pasokan air permukaan dan air tanah, diukur berdasarkan elevasi muka air sungai, waduk (Fallah \& Purwanto, 2018; Muryani, Sarwono, \& Hastuti, 2016; Nurrohmah \& Nurjani, 2017). Berdasarkan penyebab dan dampak, kekeringan diklasifikasikan menjadi kekeringan secara alamiah dan kekeringan karena ulah manusia. (Adi, 20ll; Purwaningsih, 2014; Savitri \& Pramono, 2018). Kekeringan alamiah dibedakan menjadi: (a) kekeringan meteorologis, yaitu kekeringan yang berkaitan dengan tingkat curah hujan yang terjadi berada di bawah kondisi normalnya pada suatu musim; (b) kekeringan hidrologis, yaitu kekeringan yang berkaitan dengan berkurangnya pasokan air permukaan dan air tanah; (c) kekeringan agronomis, yaitu berhubungan dengan kelengasan tanah; dan (d) kekeringan sosial ekonomi, yaitu berkaitan dengan kondisi dimana pasokan komoditi ekonomi kurang dari kebutuhan normal akibat terjadinya kekeringan meteorologi, hidrologi dan agronomi (pertanian) (Adi, 20Il; Zubaidah, 2014; Oktaviani, 20I5; Fallah \& Purwanto, 20I8).

Beberapa penelitian tentang nilai ekonomi air telah dilakukan diantaranya adalah di hutan larangan adat kenegerian Rumbio nilai ekonomi airnya sebesar Rp. 5.865.8I4.050/tahun (Arfitryana, Sribudiani, \& Mukhamadun, 2015); penelitian di hutan produksi Landono, Desa Lakomea, Kecamatan Landono, Kabupaten Konawe Selatan nilai ekonomi pemanfaatan air sebesar Rpl6.197.930,72/tahun (Kasim, Midi, \& Juliana, 20I5); penelitian di PT Pertamina dari kawasan Hutan Lindung Sungai Wain (HSW) nilai ekonomi air yang dimanfaatkan oleh masyarakat adalah sebesar Rp. 3 I.054.573.872 / tahun (Yusuf, 2010). Melihat hal tersebut dapat dilihat betapa mahalnya nilai pemanfaatan air rumah tangga. Kekeringan yang terjadi, ini akan menjadi masalah ketika air tidak dapat memenuhi kebutuhan hidup manusia seharihari (Wahyudi, 2009; Zulfikar, 2016; Fithriah, 20II; Susetyaningsih, 20I2). Oleh karena itu tujuan dari penelitian ini adalah untuk mengetahui nilai ekonomi pemanfaatan air rumah tangga di Kecamatan Kradenan, Kabupaten Grobogan. Diharapkan dengan diketahuinya besaran nilai ekonomi pemanfaatan air rumah tangga, maka pemerintah dan masyarakat akan mengetahui seberapa besar manfaat air tersebut dan bagaimana cara untuk menjaga kelestariannya agar air selalu ada setiap tahun dan lestari.

\section{METODE PENELITIAN}

\section{A. Lokasi dan Waktu Penelitian}

Penelitian dilaksanakan pada tahun 2018, di Springshed Mindik, Kecamatan Kradenan, Kabupaten Grobogan. Lokasi dapat di lihat pada Gambar I. 


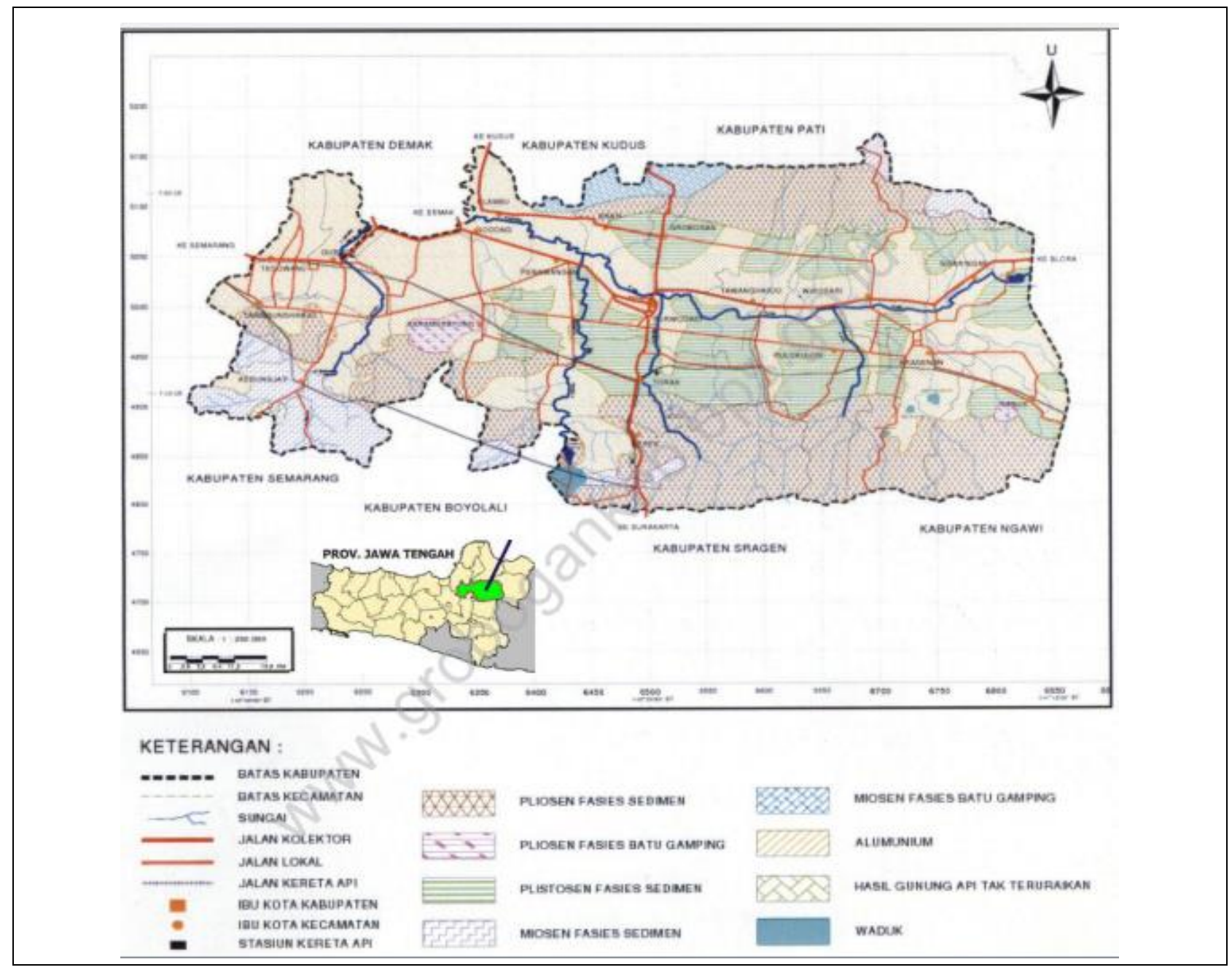

Gambar I. Lokasi Penelitian, Kecamatan Kradenan, Kabupaten Grobogan Figure I. Location of research Kradenan Sub-disrict, Grobogan Districts (Purwanto et al., 20I8)

\section{B. Pengumpulan Data}

Pengumpulan data dilakukan dengan melakukan wawancara secara tertutup. Responden pada penelitian ini berjumlah 42 orang dan diambil secara purposive dengan kriteria penduduk di kecamatan Kradenan, mengambil air di sendang baik dengan menggunakan pompa air maupun dengan menimba langsung ke sendang. Responden yang dipilih adalah penduduk di dusun Ngaram-ngaram (Desa Crewek), Dusun Dagen (Desa Keyongan), Dusun Gabus (Desa Tawangharjo), Dusun Gabus Rowo (Desa Rejosari), Dusun Kragilan (Desa Rejosari),
Dusun Gulangan (Desa Rejosari). Data primer yang dikumpulkan antara lain adalah data kebutuhan air masing-masing rumah tangga, jarak rumah ke sumber air, cara pengambilan air ke sumber mata air, harga air tangki yang biasa di beli masyarakat, jumlah anggota rumah tangga. Selain itu juga dilakukan validasi data dengan tokoh kunci seperti ketua RT, ketua RW dan kadus.

Selain itu juga dilakukan pengambilan data sekunder ke dinas terkait seperti BPS, BAPPEDA, Dinas Kehutanan Grobogan dan kelurahan. Data sekunder yang dikumpulkan adalah jumlah rumah tangga pemanfaat air, jumlah penduduk, kondisi geografis. 


\section{Analisis Data}

Analisis data dilakukan dengan menghitung persepsi masyarakat pada masingmasing penggunaan air dilakukan dengan menilai kesediaan membayar (Willingness To Pay/WTP) atas pemanfaatan air untuk kebutuhan rumah tangga dalam bentuk deskriptif kualitatif dan kuantitatif. Nilai ekonomi hasil air dari springshed Mindik dengan rumus di bawah ini: (Lopis, Laoh, \& Sondakh, 2017; Putri, 2012; Pratama et al., 2018).

\section{NART $=$ RTPA $\times$ JA $\times$ KP $\times$ HAS}

Keterangan:

(Remarks):

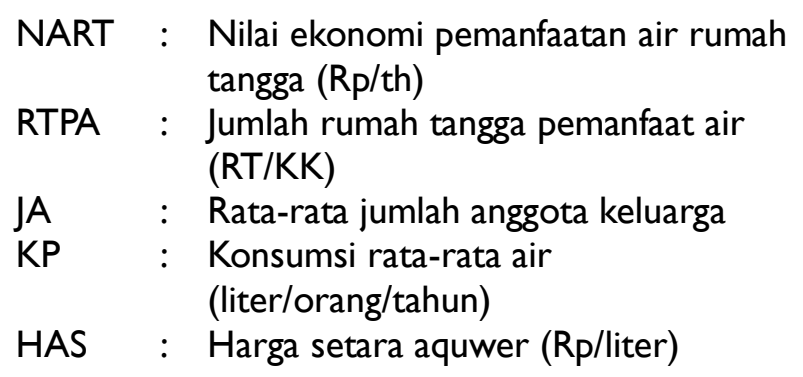

\section{HASIL DAN PEMBAHASAN}

\section{A. Kondisi Umum Lokasi Penelitian}

Kecamatan Kradenan merupakan salah satu kecamatan di Kabupaten Grobogan yang termasuk daerah yang mengalami kekeringan pada musim kemarau (Adi, 201I; Hazami, 2019; Mustofa, 2019). Kecamatan Kradenan berbatasan sebelah barat dengan Kecamatan Pulokulon, sebelah utara dengan Kecamatan Wirosari, sebelah timur dengan Kecamatan Gabus dan sebelah selatan dengan Kecamatan Tangen Kabupaten Sragen. Kecamatan Kradenan termasuk daerah dataran rendah dengan ketinggian sampai $50 \mathrm{mdpl}$ (BPS, 2018).
Kecamatan Kradenan mempunyai luas 10.773,67 Ha dengan luas lahan sawah seluas 3.966,25 Ha dan lahan tanah kering seluas 6.807,42 Ha (BPS, 20I8). Dilihat dari kondisi pengairan yang ada, pada musim kemarau sistem pengairan lahan pertanian yang ada tidak dapat berfungsi secara maksimal. Lahan pertanian sawah seluas 3.966,25 $\mathrm{Ha}$ dapat digolongkan ke dalam sawah irigasi 921,25 Ha dan sawah tadah hujan 3.045,00 $\mathrm{Ha}$. Sementara untuk lahan kering terdiri dari tegalan/kebun I.367,28 $\mathrm{Ha}$; pekarangan 2.019,II Ha; hutan negara 2.47I,40 $\mathrm{Ha}$; kolam/tambak 3,55 Ha; lainnya 946,08 $\mathrm{Ha}$ (BPS, 20l8).

Jumlah penduduk Kecamatan Kradenan 82.744 jiwa dengan kepadatan penduduk 768 jiwa $/ \mathrm{km}^{2}$. Dilihat dari kepadatan penduduknya, Kecamatan Kradenan termasuk kepadatan penduduk yang tinggi yaitu di atas 400 jiwa/ $/ \mathrm{km}^{2}$ (Paimin, Pramono, Purwanto, \& Indrawati, 20I2).

\section{B. Kondisi Masyarakat Ketika Musim kemarau}

Awal bulan Juli 2018, ketersediaan air di springshed Mindik, Kecamatan Kradenan mulai berkurang. Masyarakat mulai mengambil air secara manual yaitu dengan mengambil air langsung ke sendang. Pengambilan air biasanya dilakukan dengan memakai pompa air yang disalurkan ke masing-masing rumah penduduk (Gambar 2). Tetapi dengan berlangsungnya musim kemarau, air tidak dapat lagi disedot langsung ke masing-masing rumah penduduk sehingga harus dilakukan dengan menggunakan timba (Gambar 3). Penduduk yang mengambil air ada yang berjalan kaki dengan menggendong klenting atau jerigen (Gambar 4) dan ada pula yang memakai sepeda motor dengan menggunakan rombong (Gambar 5). 


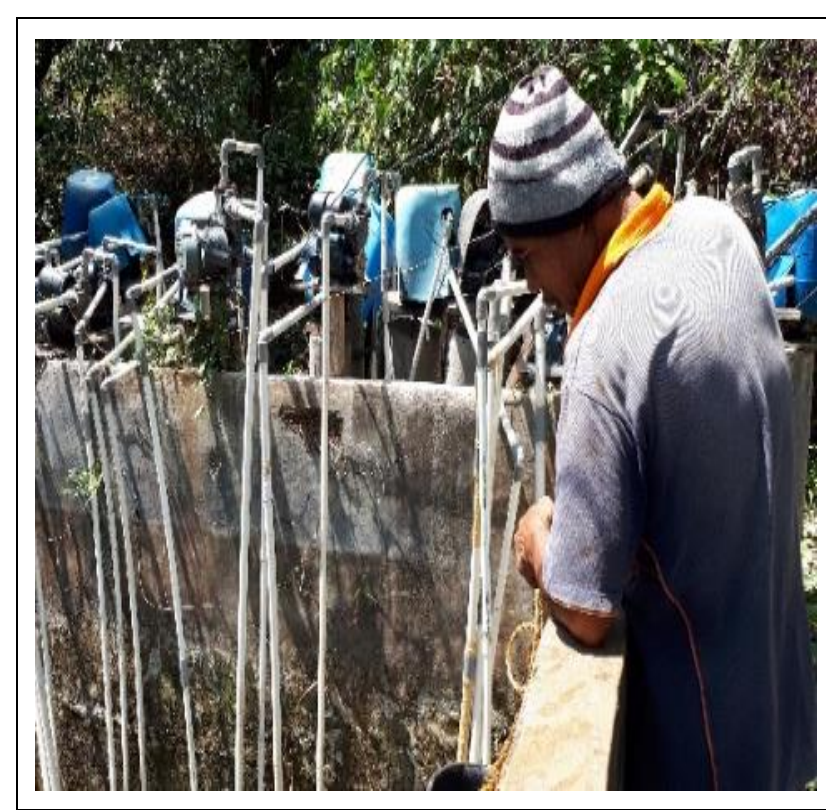

Gambar 2. Pengambilan air menggunakan pompa air ketika musim penghujan

Figure 2. Taking water usually uses a water pump during the rainy season

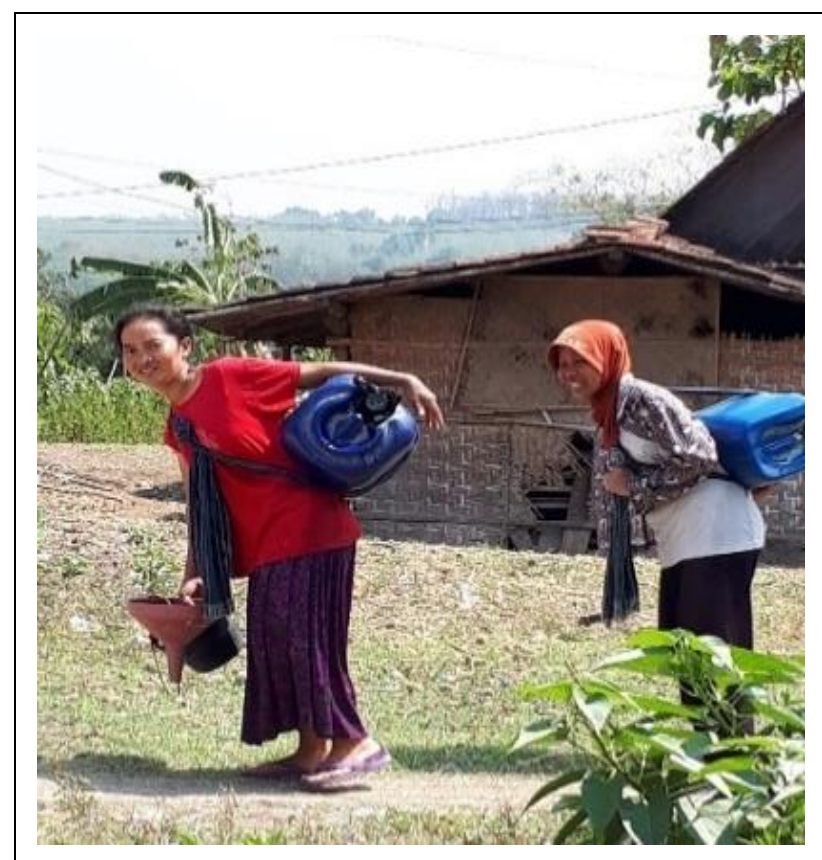

Gambar 4. Pengambilan air dengan menggunakan jerigen dengan berjalan kaki

Figure 4. Taking water using jerry can on foot

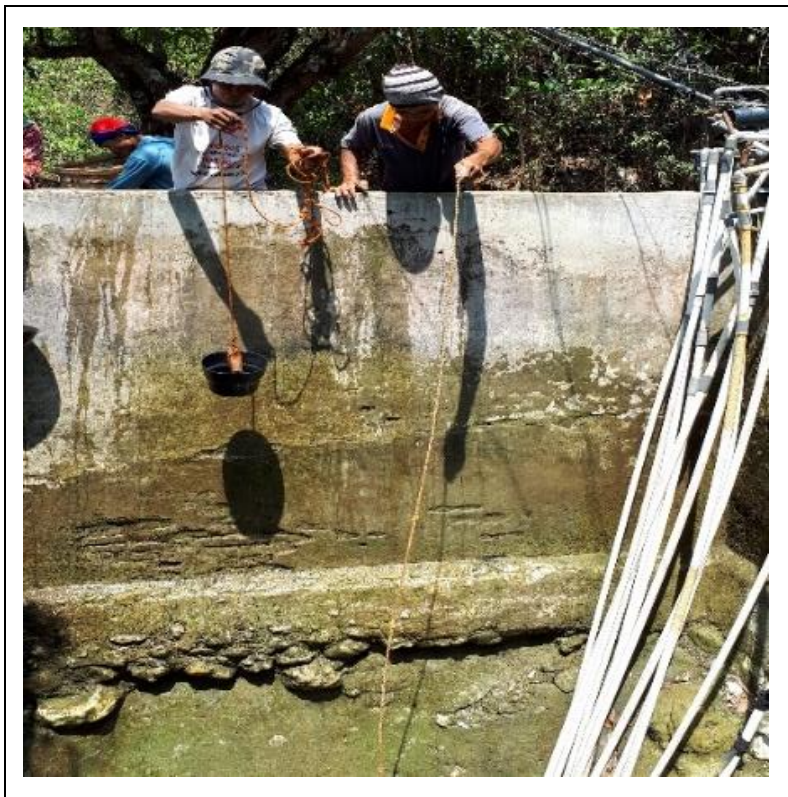

Gambar 3. Pengambilan air menggunakan timba ketika musim kemarau karena debit air berkurang banyak

Figure 3. Taking water using buckwheat during the dry season because the water flow decreases a lot

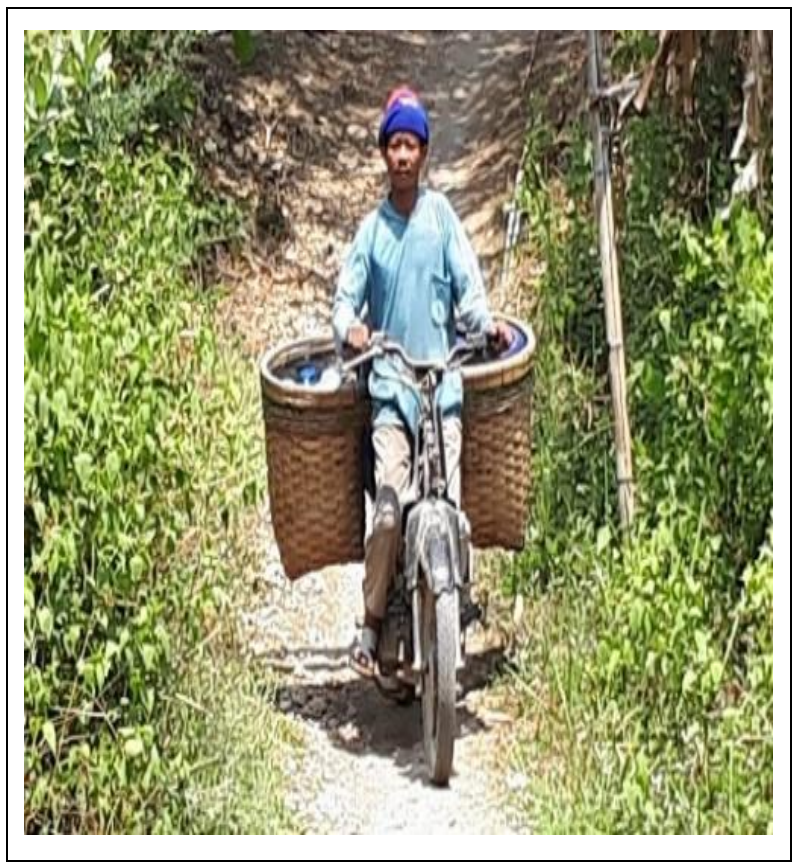

Gambar 5. Pengambilan air dengan menggunakan kendaraan bermotor, jerigen dimasukkan ke rombong

Figure 5. Taking water using a motorized vehicle, jerry cans are put into rombong 
Pada musim kemarau lahan-lahan tegal dibiarkan bero, karena lahan sudah tidak dapat ditanami lagi dengan kurangnya air untuk tanaman, selain itu sistem pengairan lahan pertanian tidak berfungsi maksimal (BPS, 2018).

Di beberapa wilayah seperti di Desa Ngaram-ngaram sudah dilakukan kegiatan penanaman sejak tahun 2006 ketika ada kegiatan gerhan, seluas 50 ha dari 75 ha dengan ditanamani tanaman jati. Kegiatan penanaman tersebut sudah berpengaruh terhadap kondisi iklim dan sumber mata air yang ada di wilayah tersebut (Riyanto \& Supangat, 2019). Tetapi ketika musim kemarau panjang, kondisi tersebut belum membantu keberlangsungan sumber mata air yang ada.

\section{Nilai Ekonomi Pemanfaatan Air Rumah Tangga}

Nilai ekonomi pemanfaatan air rumah tangga sekecamatan Kradenan dilihat dari jumlah rumah tangga pemanfaat air, konsumsi rata-rata air, rata-rata jumlah anggota keluarga, diperoleh sebesar Rp I66.7|7.923.80I,00/tahun. Secara lebih jelas dapat dilihat pada Tabel I.

Tabel 2. Nilai ekonomi pemanfaatan air rumah tangga se Kecamatan Kradenan Table 2. Economic value of household water utilization in Kradenan Sub District

\begin{tabular}{ll}
\hline Uraian (description) & Satuan (unit) \\
\hline Jumlah Rumah tangga pemanfaat air (RT/KK) & 20.686 \\
Konsumsi rata-rata air (liter/orang/tahun) & 53.023 \\
Harga setara air (Rp/liter) & 38 \\
Rata-rata jumlah anggota keluarga & 4 \\
Nilai ekonomi pemanfaatan air rumah tangga (Rp/th) & 166.717 .923 .801 \\
\hline
\end{tabular}

Sementara itu berdasarkan hasil survei, kebutuhan air rumah tangga di Kecamatan Kradenan sebesar 12.186.982,73 liter/hari. Kebutuhan air perhari rata-rata penduduk di kecamatan Kradenan sebesar 147,29 liter/hari untuk kebutuhan MCK (Tabel 2). Kebutuhan air perhari di Kecamatan Kradenan tidak jauh besar dengan hasil survei dari Direktorat Pengembangan Air Minum Ditjen Cipta Karya pada tahun 2006 yang menunjukkan bahwa setiap orang Indonesia mengkonsumsi air rata-rata sebanyak 144 liter per hari (Ciptakarya PU, 2007). Begitu juga jumlah kebutuhan orang perliter per hari di kecamatan Depok, kabupaten Sleman sebesar |46,01-147,08 liter/orang/hari (Yudistira \& Adji, 20।3).

\section{Tabel 3. Kebutuhan air rumah tangga se Kecamatan Kradenan}

Table 3. The water needs of households in Kradenan sub district

\begin{tabular}{ll}
\hline Uraian (description) & Satuan (unit) \\
\hline Jumlah penduduk (jiwa) & 82.744 \\
Jumlah kebutuhan air perhari (liter/jiwa/hari) & 147,29 \\
Jumlah kebutuhan air penduduk (liter/hari) & $12,186,982.73$ \\
\hline
\end{tabular}


Ketersediaan air di Grobogan 725,9 MCM, kebutuhan air untuk pertanian 2 kali tanam 622,6 MCM; kebutuhan air untuk industri I,6 MCM; kebutuhan air untuk domestic 59,7 MCM; total kebutuhan air 684 MCM. Kondisi ini termasuk kritis dengan indeks kekritisan air 94,2. Indeks kekritisan air (IKA) merupakan merupakan rasio antara total kebutuhan dengan ketersediaan air. Nilai IKA kurang dari 0,50 menunjukkan kondisi yang belum kritis, nilai IKA antara 0,50-0,75 mendekati kritis, nilai IKA antara 0,75-I,00 kritis, dan lebih dari I,00 sangat kritis (SK No 52/Kpts-II/200I, 200I). Ketersediaan air ditentukan oleh kondisi neraca air yang direpresentasikan dalam komponen curah hujan, evapotranspirasi, aliran permukaan, perkolasi, dan simpanan air tanah. Sedangkan kebutuhan air ditentukan oleh kebutuhan air penduduk, kebutuhan air industri, dan kebutuhan air untuk pertanian (Rejekiningrum, 2014; Samekto \& Winata, 2010; Isnin et al., 20I2). Kondisi curah hujan di berdasarkan data tahun 2006-2014, curah hujan rata-rata tahunan di lokasi kajian 2.025 $\mathrm{mm}$ dengan rata-rata hari hujan III hari. Menunjukkan bahwa sebagian besar curah hujan yang jatuh di lokasi penelitian akan hilang melalui proses evapotranspirasi yaitu sebesar 57,26\% (I.049,6 mm), sedangkan potensi terjadinya aliran permukaan tahunan hanya sebesar $42,74 \% \quad(783,44 \quad \mathrm{~mm})$ (Purwanto \& Supangat, 2017).

\section{KESIMPULAN DAN SARAN}

\section{A. Kesimpulan}

Kebutuhan air rumah tangga di Kecamatan Kradenan sebesar 12.186.982,73 liter/hari. Nilai ekonomi pemanfaatan air rumah tangga sekecamatan Kradenan dilihat dari jumlah rumah tangga pemanfaat air, konsumsi rata-rata air, rata-rata jumlah anggota keluarga, diperoleh sebesar Rpl66.7I7.923.80I,00/ tahun dengan kebutuhan air per harinya adalah 147,29 liter/jiwa/hari.

\section{B. Saran}

Kebutuhan air merupakan sarana vital yang sangat diperlukan masyarakat. Melihat hal itu maka antar masyarakat dan aparat perlu melakukan kegiatan yang bertujuan untuk menjaga kelestarian sumber air seperti menanami sekitar sumber mata air dengan tanaman yang dapat menyimpan air dalam jangka waktu lama agar ketika musim kemarau, kekurangan air dapat ditangani dengan baik. Untuk kedepannya perlu dilakukan kajian untuk memperbaiki kelestarian sumberdaya air di kecamatan Kradenan, agar kebutuhan air tidak menjadi masalah. Seperti dilakukannya reboisasi dan rehabilitasi lahan untuk meningkatkan kelestarian sumberdaya air.

\section{DAFTAR PUSTAKA}

Adi, H. P. (20II). Kondisi dan konsep penanggulangan bencana kekeringan di Jawa Tengah. In Seminar Nasional Mitigasi dan Ketahanan Bencana 26 Juli 20II, UNISSULA Semarang (PP. I-I0).

Arfitryana, Sribudiani, E., \& Mukhamadun. (20I5). Economic valuation of water at traditional prohibition forest Kenegerian Rumbio Pulau Sarak Village of Kampar District Kampar Regency. Jurnal Online Mahasiswa (JOM) Faperta, 2(I), I-8. Retrieved from https://jom.unri.ac.id/index.php/JOMFAP ERTA/article/view/5284

BPS. (20I8). Kecamatan Kradenan dalam angka 2018. BPS Kabupaten Grobogan.

Ciptakarya PU. (2007). Satu Orang Indonesia Konsumsi Air Rata-rata I44 Liter per 
Hari. Retrieved November 26, 2018, from

http://ciptakarya.pu.go.id/v3/news.php?i $d=|0|$

Fallah, F., \& Purwanto. (2018). Kelembagaan mitigasi kekeringan di Kabupaten Grobogan. Jurnal Penelitian Pengelolaan Daerah Aliran Sungai, 2(2), I5 I-I 72.

Farida Rahmawati. (2003). Skenario Subsidi silang (Cross Subsidy) dalam Pembiayaan Sumberdaya Air di daerah Aliran Sungai (DAS) Kali Brantas. Jurnal Aplikasi Manajemen, 7(2), 469-474. Retrieved from http://jurnaljam.ub.ac.id/index.php/jam/a rticle/view/I 73

Fithriah, D. (20II). Perubahan Penggunaan Lahan dan Pengaruhnya terhadap Daya Dukung Lahan Untuk Mendukung Perencanaan Penataan Ruang (Studi kasus di Kota Bima Propinsi Nusa Tenggara Barat). Thesis. Institut Pertanian Bogor.

Hazami, A. (2019). Kekeringan Mulai Melanda Grobogan, Dropping Air Bersih Disalurkan. Retrieved November 7, 2019, from https://news.detik.com/berita-jawatengah/d-4607285/kekeringan-mulaimelanda-grobogan-dropping-air-bersihdisalurkan

Herlambang, A. (2009). Peran teknologi dalam penentuan kebijakan pengelolaan sumberdaya air nasional. Jurnai Air Indonesia, 5(2), 179-189. Retrieved from http://ejurnal.bppt.go.id/ejurnal20I I/ind ex.php/JAl/article/view/303/305

Isnin, M., Basri, H., \& Romano. (20I2). Nilai Ketersediaan Hasil Air dari Sub Daerah Aliran Sungai (DAS) Krueng Jreu Kabupaten Aceh Besar. Jurnal Manajemen Sumberdaya Lahan, I(2), 184-193. Retrieved from http://jurnal.unsyiah.ac.id/MSDL/article/ view/21 88

Kasim, S., Midi, L. ode, \& Juliana, J. (20I5).
Valuasi Jasa Lingkungan Hidrologis Hutan Produksi Desa Lakomea Kecamatan Landono Kabupaten Konawe Selatan. Jurnal Ecogreen, I(2), 25-38. Retrieved from http://ojs.uho.ac.id/index.php/green/arti cle/view/2840

Lopis, R. A. C., Laoh, O. E. H., \& Sondakh, M. L. (2017). Valuasi Sumberdaya Air (Studi Kasus Kawasan Mata Air Tataneyan Di Kelurahan Kinilow I, Kecamatan Tomohon Utara, Kota Tomohon). Jurnal Agri-Sosioekonomi, I3(IA), 91-100. Retrieved from https://ejournal.unsrat.ac.id/index.php/ji sep/article/view/|496|

Muryani, C., Sarwono, \& Hastuti, D. (2016). Adaptasi masyarakat terhadap bencana kekeringan di Kabupaten Grobogan, Jawa Tengah. In Prosiding Seminar Nasional Geografi UMS 2016. Upaya Pengurangan Risiko Bencana Terkait Perubahan Iklim (pp. 348-355).

Mustofa, A. (2019). Bupati bersama Bank Indonesia Droping Air Bersih di 110 Desa. Retrieved November 7, 2019, from

https://radarkudus.jawapos.com/read/20 19/09/26/I577I I/bupati-bersama-bankindonesia-droping-air-bersih-di-I I0desa

Najib, N. N. (2018). Kontribusi dan strategi Pengelolaan Jasa Lingkungan Air Tanah di Kota Makasar. Thesis. Universitas Hasanudin Makassar.

Nurrohmah, H., \& Nurjani, E. (20l7). Kajian kekeringan meteorologis menggunakan Standardized Precipitation Index (SPI) di Provinsi Jawa Tengah. Geomedia, I5(I mei 2017), I-I5.

OKtaviani, S. (20I5). Analisis kekeringan dengan menggunakan metode theory of run studi kasus DAS Ciujung. Skripsi. Universitas Sultan Ageng Tirtayasa.

Paimin, Pramono, I. B., Purwanto, \& Indrawati, 
D. R. (20/2). Sistem Perencanaan Pengelolaan Daerah Aliran Sungai. Pusat penelitian dan Pengembangan Konservasi dan Rehabilitasi (P3KR) (Vol. 53). Bogor: Pusat Penelitian dan Pengembangan Konservasi dan Rehabilitasi (P3KR). https://doi.org/ I0.1017/CBO978I I074 I 5324.004

Pratama, H., Yuwono, S. B., Kaskoyo, H., \& Bakri, S. (2018). Nilai ekonomi pemanfaatan jasa air Daerah Aliran Sungai Way Betung. Jurnal Sylva Lestari, 6(3), 9-17.

Purwaningsih, A. N. K. (20I4). Analisis kerentanan kekeringan di Sub DAS Opak Hulu pasca erupsi Merapi tahun 2010 menggunakan Sistem Informasi Geografis (Skripsi). Yogyakarta : Universitas Negeri Yogyakarta.

Purwanto, Riyanto, H. D., Supangat, A. B., Fallah, F., Jariyah, N. A., Hastanti, B.W., ... Hermawan, A. (20I8). Rencana Operasional Pengembangan (ROPg) :Teknik dan kelembagaan konservasi air dan kelembagaan konservasi air wilayah kering. Laporan Hasil Penelitian. Balai Penelitian dan Pengembangan Teknologi Pengelolaan DAS. Tidak dipublikasikan.

Purwanto, \& Supangat, A. B. (2017). Perilaku konsumsi air pada musim kemarau di Dusun Pamor, Kabupaten Grobogan. Jurnal Penelitian Sosial Dan Ekonomi Kehutanan, I4(3), I57-169.

Putri, P. R. D. (20I2). Nilai ekonomi air Daerah Aliran Sungai (DAS) Way Orok-Sub DAS Way Ratai Desa Pesawaran Indah Kecamatan Padang Cermin Kabupaten Pesawaran Provinsi Lampung. Skripsi. Universitas Lampung.

Rejekiningrum, P. (20/4). Identifikasi kekritisan air untuk perencanaan penggunaan air agar tercapai ketahanan air di DAS Bengawan Solo. In Seminar Nasional FMIPA-UT 2014, 23 September 2014, Universitas Terbuka. (Pp. 170-184).
Retrieved

from

http://repository.ut.ac.id/5026/

Riyanto, H. D., \& Supangat, A. B. (2019). Teknik Konservasi Mata Air: Studi kasus di Desa Crewek, Kecamatan Kradenan, Kabupaten Grobogan. In M. S. Dr. Agung B. Supangat, S.Hut., MT. \& M. S. Dr. I. Wayan Susi Dharmawan, S.Hut. (Eds.), Bunga Rampai Membangun Integrasi Pengelolaan DAS di Tingkat Implementatif (Cetakan I, Pp. I0I-III). Bogor: Penerbit IPB Press.

Samekto, C., \& Winata, E. S. (20I0). Potensi Sumber Daya Air di Indonesia. In Seminar Nasional: Aplikasi Teknologi Penyediaan Air Bersih untuk Kabupaten/Kota di Indonesia (pp. I-20).

Saraswaty, A. N. (20I3). Kesediaan Membayar Pelanggan Rumah Tangga untuk Pelayanan Air Bersih dari PDAM di Kabupaten Badung. E-Jurnal Ekonomi Pembangunan Universitas Udayana, 2(10), 477-49l.

Savitri, E., \& Pramono, I. B. (20/8). Identifikasi dan mitigasi kerentanan kekeringan DAS Moyo (Identification and mitigation of drought vulnerability in Moyo watershed). Jurnal Penelitian Pengelolaan Daerah Aliran Sungai, 2(2), I73-187.

SK No 52/Kpts-II/200I. (200I). Pedoman Penyelenggaraan Pengelolaan Daerah Aliran Sungai Meneteri Kehutanan.

Sriutomo, U. R. P., \& Christanto, J. (20I5). Daya dukung pertanian tanaman pangan terhadap kebutuhan pangan penduduk di kabupaten Grobogan, provinsi Jawa Tengah. Jurnal Bumi Indonesia, 4(2). Retrieved from http://lib.geo.ugm.ac.id/ojs/index.php/jbi/ article/view/328

Susetyaningsih, A. (20/2). Pengaturan Penggunaan Lahan Di Daerah Hulu Das Cimanuk Sebagai Upaya Optimalisasi Pemanfaatan Sumberdaya Air. Jurnal Konstruksi Sekolah Tinggi Teknologi Garut, 
I0(I). $\quad$ https://doi.org/10.1017/ CBO978I I074I 5324.004

Susilastuti, D., Karno, \& Diana, T. B. (20|4). Analisis Peran Petani dalam Pengelolaan Air Irigasi (Studi Ekonomi dan Ekologi Air Irigasi di Kabupaten Bekasi). AGRISIA - Jurnal IImu-IImu Pertanian, 7(I), I-I3.

Wahyudi, H. (2009). Kondisi dan Potensi Dampak Pemanfaatan Air Tanah di Kabupaten Bangkalan. Jurnal APLIKASI, 7(I), 14-19. Retrieved from http://iptek.its.ac.id/index.php/jats/articl e/view/2753/21 I 9

Yudistira, A., \& Adji, T. N. (20 I3). Kajian Potensi Dan Arahan Penggunaan Air tanah Untuk Kebutuhan Domestik Di Kecamatan Depok Kabupaten Sleman. Jurnal Bumi Indonesia, 2(2), I04-II2. https://doi.org/ I 0.10 I 7/CBO978 I I 074 I 5324.004

Yusuf, S. (2010). Nilai Ekonomi Air Hutan Lindung Sungai Wain di Balikpapan Kalimantan Timur. Jurnal Kehutanan Tropika Humida, 3(2), 2II-2I6.

Zubaidah, A. (20I4). Prediksi Banjir dan kekeringan Menggunakan Model Prediksi Curah hujan Bulanan. In Bunga Rampai: Pemanfaatan Data Penginderaan Jauh Untuk Mitigasi Bencana (pp. I I-20).

Zulfikar, M. S. (2016). Kebijakan PEMDA Gunungkidul dalam menanggulangi kekeringan di Desa Girisuko, Kecamatan Panggang, Kabupaten Gunungkidul, DIY. Skripsi. Universitas Islam Negeri Sunan Kalijaga Yogyakarta. 